has a membership of nearly 30,000 , while the SPNR acts as the coordinating body for the strong Naturalists' Trusts movement which has developed so rapidly in the last ten years; it now commands a total membership of more than 20,000 and protects more than 20,000 acres. For the moment the specialist societies such as the FPS are not involved, but if the major integration can be achieved thought will have to be given to how they fit in.

\title{
The Red Book
}

\section{The World's Endangered Mammals and Birds}

THE Survival Service Commission has now made available to all who are interested its information on the world's endangered speoies of mammals and birds with the publication of the first two volumes of the Specialist's Edition of the Red Book, by IUCN in collaboration with the International Council for Bird Preservation. These two loose-leaf volumes cover 277 kinds of mammals and 321 of birds, with the promise, if the venture is successful, of further volumes to come on reptiles, insects, and plants. The loose-leaf format, of course, enables species to be removed, and new or corrected sheets to be inserted at any time, thus keeping the records up to date; the price, f3 10s each volume, includes the cost of this servicing up to December 31,1970 . For an extra charge of $£ 1$ a set of 20 strongly made and labelled plastic dividers is available for Vol. 1 (mammals) facilitating quick reference and providing protection for the sheets.

The two volumes are remarkably compact, the pages having been reduced by photo-litho process to $8.3 \times 5.8$ inches while retaining the clarity that makes for easy reading. With one page to a species, the information includes a short description of the animal, notes on distribution, status, estimated numbers, reasons for decline and other relevant facts. Both volumes achieve their declared aim of providing "in a conveniently classified form the most up to date and reliable data available on all species considered . . . . to be in danger of extinotion," and they are a tribute to the excellent work of their compilers, Noel Simon, Projects Officer of IUCN, and Colonel Jack Vincent, ICBP Liaison Officer at IUCN. Certainly they should, by spreading the vital information on endangered species round the world, stimulate a flow of information and arouse an interest in our endangered wildlife.

Orders should be sent to IUCN, 1110 Morges, Vaud, Switzerland; orders for the set of two will be sent specially boxed at no extra charge.

\section{OFFICIAL HELP FOR THE BALD EACLE}

In an effort to stop the continuing decline of the bald eagle in the USA, the Secretary of the Interior, Mr Stewant $\mathrm{L}$. Udall, this spring made an order closing off all eagle nesting sites in nattional wildilife refuges to eliminate disturbance. No timber cutting was permitted within half a mile of a nest, and trees that are potential nesting sites are to be preserved. 